\title{
Cryptic diversity of the tube-dwelling polychaete Phyllochaetopterus in the Shinkai Seep Field, Mariana Trench
}

\author{
Hiromi Kayama Watanabe ${ }^{1, *}$, Chong $\mathrm{Chen}^{1}$, Eijiroh Nishi ${ }^{2} \&$ Yasuhiko Ohara ${ }^{3,4,5}$ \\ ${ }^{1}$ X-STAR, Japan Agency for Marine-Earth Science and Technology (JAMSTEC), 2-15 Natsushima-cho, Yokosuka-shi, Kanagawa 237-0061, Japan \\ ${ }^{2}$ Yokohama National University, 79-1 Tokiwadai, Hodogaya, Yokohama, Kanagawa 240-8501, Japan \\ ${ }^{3}$ Hydrographic and Oceanographic Department of Japan, 3-1-1 Kasumigaseki, Chiyoda-ku, Tokyo 100-8932, Japan \\ ${ }^{4}$ Research Institute for Marine Geodynamics (IMG), Japan Agency for Marine-Earth Science and Technology (JAMSTEC), 2-15 Natsushima- \\ cho, Yokosuka-shi, Kanagawa 237-0061, Japan \\ ${ }^{5}$ Nagoya University, Furo-cho, Chikusa-ku, Nagoya 464-8602, Japan
}

Received 26 May 2020; Accepted 2 September 2020 Responsible Editor: Waka Sato-Ohkoshi

doi: $10.3800 /$ pbr. 16.73

\begin{abstract}
Phyllochaetopterus (Annelida: Chaetopteridae) is a diverse genus of tube-dwelling polychaetes found in a wide range of marine environments from subtidal to abyssal depths, including chemosynthesis-based ecosystems. The Shinkai Seep Field (SSF) is a serpentinite-hosted system in the Mariana Trench, where the deepest-known Phyllochaetopterus polychaetes inhabit the surfaces of brucite/carbonate chimneys. Despite all specimens collected from SSF being morphologically consistent with $P$. polus originally described from a deep-sea hot vent on the Mid-Atlantic Ridge, molecular barcoding using the mitochondrial cytochrome $c$ oxidase subunit I (COI) gene revealed at least three cryptic lineages, none of which corresponded to P. polus. Phylogenetic reconstruction recovered $P$. polus embedded among the three SSF lineages, confirming their close relationship. These results warrant careful examination of Phyllochaetopterus from other regions using integrative taxonomy in order to understand its true diversity and pinpoint further taxonomically informative morphological characters.
\end{abstract}

Key words: Chaetopteridae, deep sea, serpentinization, chemosynthesis-based ecosystem

Phyllochaetopterus is a diverse polychaete genus with about 20 valid species living in a wide range of marine environments from shallow to deep waters, including chemosynthesis-based ecosystems such as hydrothermal vents and hydrocarbon seeps (Nishi \& Rouse 2014). The Shinkai Seep Field (SSF) is the world's deepest known serpentinite-hosted seep field, located at a depth of $\sim 5700 \mathrm{~m}$ deep in the southern Mariana forearc on the landward slope of the Mariana Trench (Ohara et al. 2012). The SSF is characterized by both sedimented area dominated by the vesicomyid clam, Abyssogena mariana (Okutani et al. 2013), and rocky areas with brucite/carbonate chimneys where Phyllochaetopterus worms and the provannid snail, Provanna cingulata, are the most conspicuous animals (Fig. 1; Okumura et al. 2016; Chen et al. 2016). Though deeper than the carbonate compensation depth, these chimneys are sustained by geofluid input through slow seepage, enriched with hydrogen and methane (Okumura et al. 2016). The SSF represents the deepest record $(5687 \mathrm{~m})$ of the genus Phyllochaetopterus and is over $1.5 \mathrm{~km}$ deeper than

\footnotetext{
* Corresponding author: Hiromi Kayama Watanabe; E-mail,
} hwatanabe@jamstec.go.jp
Phyllochaetopterus polus from the Ashadze-1 field, a serpentinite-hosted hydrothermal vent field on the Mid-Atlantic Ridge (4085 m; Morineaux et al. 2010). The taxonomic identity and systematic position of the SSF Phyllochaetopterus, however, have not been examined to date. Here, we present the first results of morphological and molecular examinations, using the barcoding region of the mitochondrial cytochrome oxidase $c$ subunit I (COI) gene, for previously unidentified SSF Phyllochaetopterus specimens.

Phyllochaetopterus tubes were collected from two brucite/ carbonate chimneys (type II chimneys 'Chim 4' and 'Chim 10 ' in Okumura et al. 2016) located in a single chimney site ('CH site 3' in Okumura et al. 2016) during dives \#1402 (Chim 10, July 2014) and \#1433 (Chim 4, July 2015) of the deepsubmergence vehicle (DSV) Shinkai 6500 in R/V Yokosuka cruises YK14-13 and YK15-11. A detailed in situ visual observation of the Phyllochaetopterus tubes was also performed during the remotely operated vehicle (ROV) Kaiko (with vehicle $M k-I V$ ) dive \#709 on-board R/V Kairei cruise KR16-04 (Fig. 1). The mineral compositions of both chimneys were similar, and they are thought to have formed from the same source of geofluids (Okumura et al. 2016). Some tubes among 

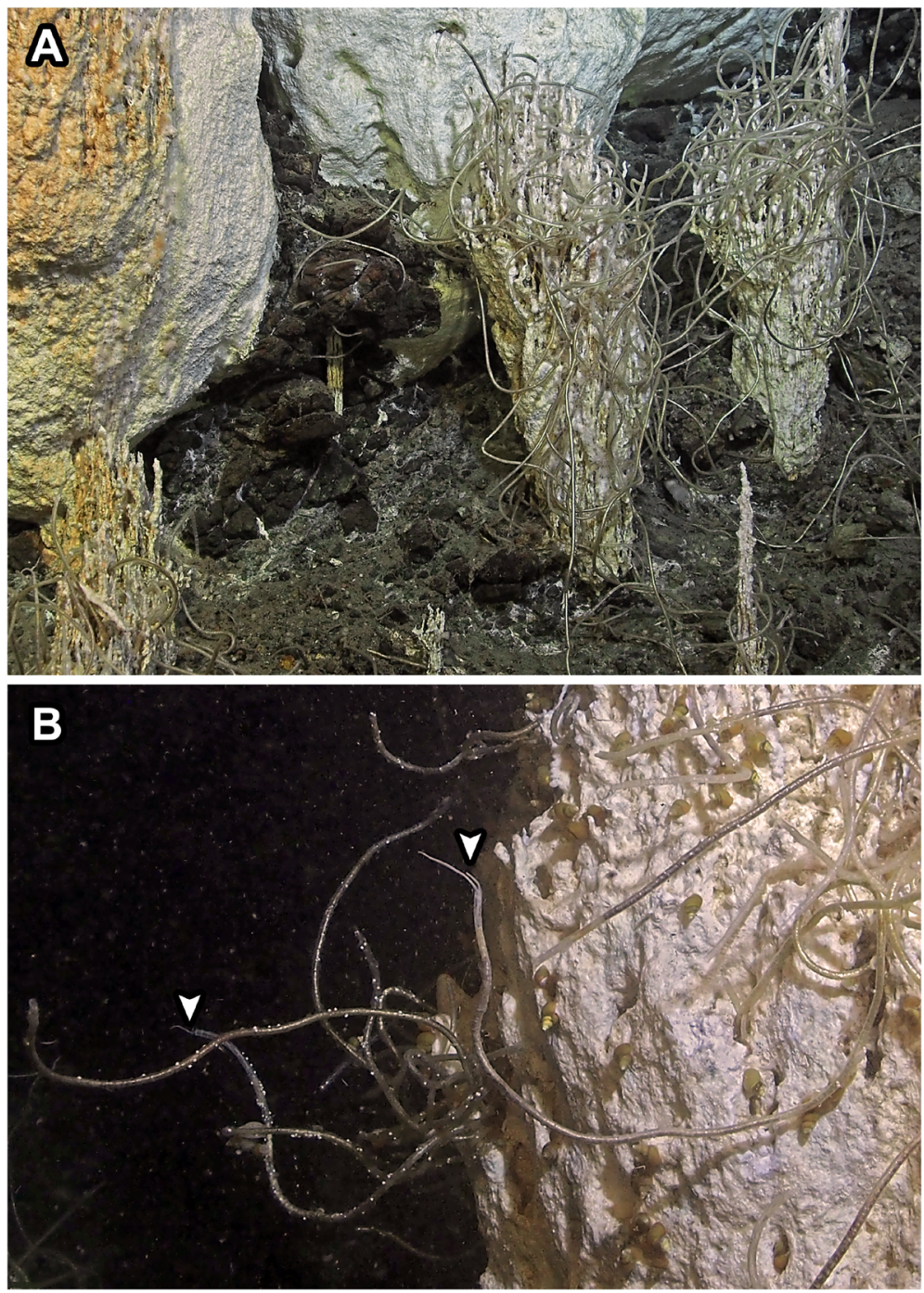

Fig. 1. In situ observations of Phyllochaetopterus in the Shinkai Seep Field. A: Brucite/carbonate chimneys in 'CH site 3' (Okumura et al., 2016) overgrown by tubes of Phyllochaetopterus; B: Close-up of Phyllochaetopterus worms, arrowheads indicating live worms with extended palps visible. Photos taken on ROV Kaiko dive \#709 in R/V Kairei KR16-14 cruise.

the many collected were empty, yielding eight live worms in Shinkai 6500 dive \#1402 and 32 live worms in \#1433, which were preserved in $99.5 \%$ ethanol. Genomic DNA was extracted, and COI barcoding was carried out following methods detailed in Chen et al. (2019), using the 'universal' primers designed by Folmer et al. (1994) with an annealing temperature of $50^{\circ} \mathrm{C}$.

Sequence variability among the SSF specimens and other closely related species with available sequences on GenBank, were compared after alignment by Clustal X in MEGA 7.0.26 (Kumer et al. 2016) resulting in a final alignment of 525 bp (GenBank accession numbers MT491391-MT491430). A maximum likelihood (ML) phylogeny was reconstructed in MEGA 7.0.26 with 2,000 bootstrap replicates using the Hasegawa-Kishino-Yano substitution model with a Gamma distribution and invariant sites as selected by the Model Selection function in MEGA 7.0.26. Phylogenetic reconstruction by Bayesian inference was carried out by MrBayes (Ron- quist et al. 2012) with 5,000,000 Markov chain Monte Carlo (MCMC) generations; the first 10,000 generations were removed as burn-in. A Bayesian implementation of the Poisson tree process (bPTP) model (Zhang et al. 2013) and the Automatic Barcoding Gap Delimitation (ABGD; Puillandre et al. 2012) methods were carried out on the respective webservers to identify barcoding gaps among sequences and estimate species delimitation. The parameters for bPTP were set to 100,000 generations, with the first 1,000 generations removed as burn-in. The ABGD $\mathrm{P}_{\min }$ and $\mathrm{P}_{\max }$ were set to 0.001 and 0.1 , respectively.

All SSF specimens examined shared the morphological characteristics of $P$. polus, originally described from the Ashadze-1 field in the Mid-Atlantic Ridge (Morineaux et al. 2010). These include having minute second antennae, nine chaetigers in the anterior region (A-region), two chaetigers in the middle region (B-region), trilobed notopodia in the B-region, one or two A4 chaetae in each notopodium, and 


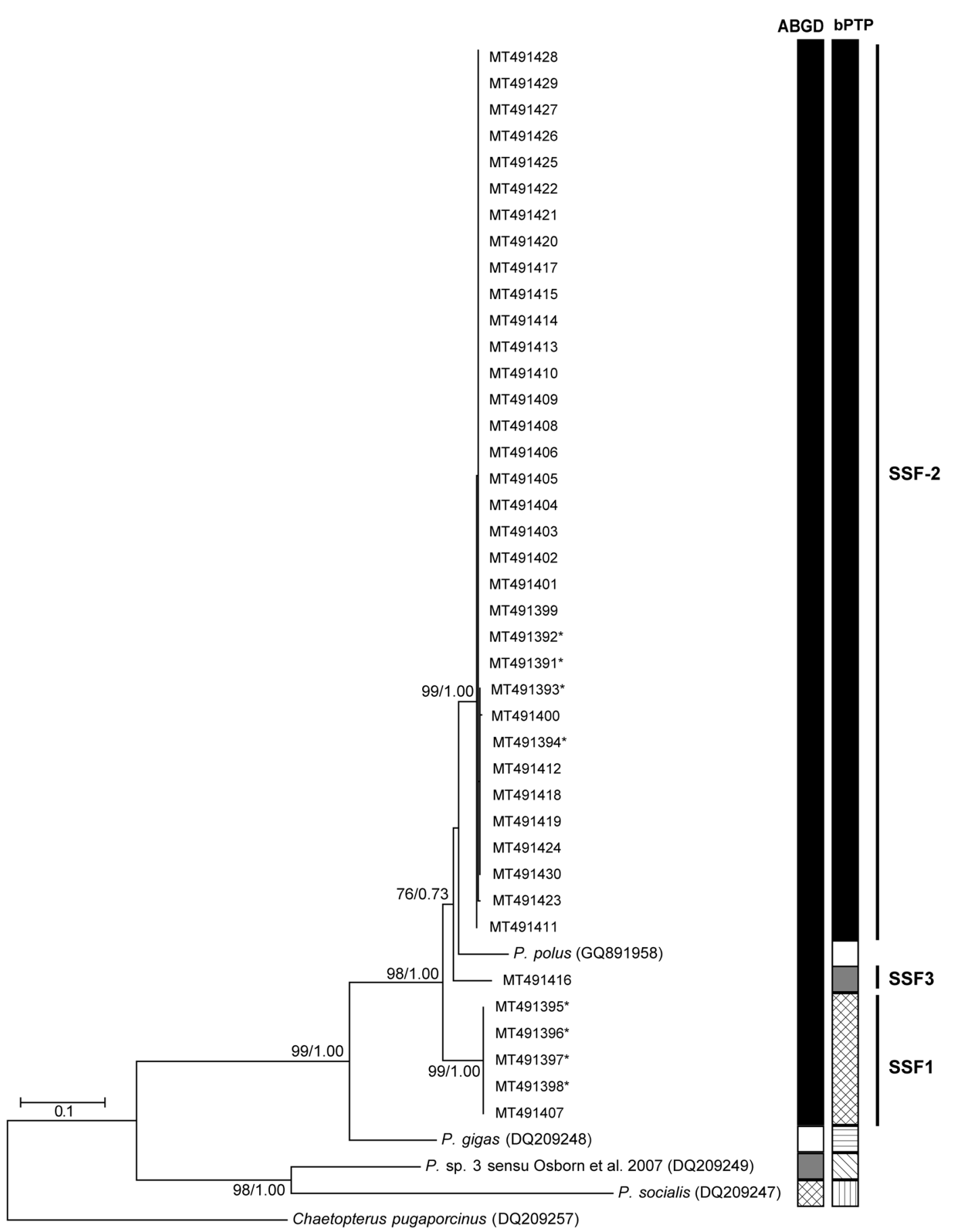

Fig. 2. Maximum likelihood tree of Phyllochaetopterus based on $525 \mathrm{bp}$ of the barcoding region of the mitochondrial COI gene (Bayesian and ML methods resulted in identical topologies). OTUs of newly obtained sequences are represented by GenBank accession numbers, with asterisks indicate the samples from Chim 4. Non-SSF sequences were retrieved from GenBank with their accession numbers shown in the parenthesis. Node values are ML bootstrap values/Bayesian posterior probabilities. Results of ABGD and bPTP species delimitation analyses are shown with colors or patterns indicate the resulting partitions. Please refer to specimen voucher information on GenBank for specific sample numbers including the U.S. Fish and Wildlife Service special use permit numbers.

more than 40 chaetigers in the posterior region (C-region). However, COI barcoding sequences revealed three distinct, cryptic lineages (Fig. 2), which we tentatively call SSF1 (five individuals), SSF2 (34 individuals), and SSF3 (one individual). A clear barcoding gap $>7 \%$ (up to $41 \mathrm{bp}$ out of
$525 \mathrm{bp}$, average $39.206 \pm 0.585)$ in the pairwise uncorrected distances was observed between SSF1 and SSF2. There was no sequence variation among the SSF1 individuals and only a maximum variation of $3 \mathrm{bp}$ was seen in SSF2. The third SSF lineage, SSF3, exhibited $>8 \%$ pairwise distances and a 
$43.000 \pm 0.000$ bp difference to SSF1, and $>6 \%$ pairwise distances and $32.265 \pm 0.567 \mathrm{bp}$ difference to SSF2.

Phylogenetic reconstruction (Fig. 2) confirmed the close relationships between P. polus and the three SSF Phyllochaetopterus lineages, as inferred by their morphological similarity. Phyllochaetopterus polus was recovered sister to SSF2, the pair in turn being sister to SSF3, while SSF1 was the most basal of the four. The uncorrected sequence divergences between $P$. polus and the three SSF lineages were $>8 \%$ and $46.000 \pm 0.000 \mathrm{bp}$ for SSF1, $>6 \%$ and $34.265 \pm 0.567 \mathrm{bp}$ for SSF2, and $>8 \%$ and 46 bp for SSF3. Although such divergences are suggestive of these lineages representing different species, results from the two species delimitation methods used were contradictory. The bPTP analysis indicated that all four lineages correspond to separate species, whereas the ABGD analysis suggested that all four lineages represent intraspecific variation of $P$. polus (Fig 2).

Similar cases of cryptic diversity have been reported for other animals in deep-sea chemosynthesis-based communities. For example, the vesicomyid clams Phreagena soyoae and Phreagena okutanii are a pair of sister-species that overlap morphologically and co-occur in hydrocarbon seeps in Sagami Bay (Kojima \& Ohta 1997). Morphometric analyses showed that although the two species differed in shell form statistically, some individuals from both species had overlapping features and were difficult to distinguish based on morphology alone. The microhabitats preferred by the two species in Sagami Bay differed in both temperature and salinity (Kojima \& Ohta 1997, Watanabe et al. 2013), indicating ecological and physiological differences such as thermo- and/ or osmoregulation capabilities, between the two clam species. Previous studies found no underlying geochemical differences between the two brucite/carbonate chimneys hosting Phyllochaetopterus in mineralogy and fluid chemistry, and the stable isotopic compositions of the animals did not differ between the two chimneys (Okumura et al. 2016, Onishi et al. 2018). As such, little evidence for differences in habitat preferences among SSF Phyllochaetopterus lineages exists now and we also cannot exclude the possibility of sampling bias regarding their preferred distributions. Nevertheless, it is possible that finer investigations of local conditions may reveal fine differences in their microhabitats.

Carbon and nitrogen stable isotopic compositions of $P$. polus from the Ashadze-1 vent field on the Mid-Atlantic Ridge were similar to the SSF lineages, indicating that they are detritus feeders mainly consuming chemoautotrophic bacteria (Fabri et al. 2011, Onishi et al. 2018). Although the sulfur $\left(\delta^{34} \mathrm{~S}\right)$ stable isotopic composition differed between $P$. polus $(+6.87 \%)$ and the SSF lineages $(+21.6 \%$, Fabri et al. 2011; Onishi et al. 2018), this likely reflect geochemical differences between hydrothermal vents, where $P$. polus occurs, and the SSF which is a serpentinite-hosted seep. The former, Ashadze-1 field is a high-temperature, black-smoker type serpentinite-hosted hydrothermal vent field with minerals in chimneys showing sulfur isotopic compositions $\left(\delta^{34} \mathrm{~S}\right)$ ranging from $+3.7 \%$ o to $+14.1 \%$ o (Fouquet et al. 2008, Firstova et al. 2013), whereas the SSF is a low-temperature serpentinitehosted seep field with the fluid $\delta^{34} \mathrm{~S}$ isotopic composition of $+20.3 \%$ to $+20.4 \%$ (Onishi et al. 2018). Taken together, these suggest that the Phyllochaetepterus lineages in the SSF have similar feeding ecology with the closely related $P$. polus, from which they appear to be morphologically indistinguishable based on characters currently used to differentiate Phyllochaetopterus species. Nevertheless, they indeed rely on local food sources available at the different chemosynthesis-based ecosystems they live in.

Cryptic speciation is common in annelids and has also been documented in other vent and seep polychaetes, such as the amphinomid genus Archinome (Borda et al. 2013) and the ampharetid genus Amphisamytha (Zhou et al. 2019). More in-depth examinations of the morphological characters may reveal reliable morphological characteristics that differentiate the lineages discovered by DNA barcoding, and in some cases life history characters may prove to be the key (Sigwart \& Chen 2018). Our results warrant further studies of the global Phyllochaetopterus from multiple perspectives including not only morphology and molecular barcoding but also physiological and ecological aspects, in order to better understand its diversity and the differences among lineages.

\section{Acknowledgements}

We thank the captain and crew of R/V Yokosuka and R/V Kairei, the operation teams of DSV Shinkai 6500 and ROV Kaiko Mk-IV, and all on-board scientists for their help with our study during cruises YK14-13, YK15-11, and KR16-04 led by Y.O. The Shinkai Seep Field is a part of the Mariana Trench Marine National Monument of the United States of America and we thank the U.S. Fish and Wildlife Service for approving our study in the monument under the special use permits \#12541-14001 (for YK14-13 cruise), \#1254115002 (for YK15-11 cruise), and \#12541-16002 (for KR1604 cruise). Sample numbers under these permits used in the present study were: \#12541-14001-6K1402-B04-1 to B04-4, \#12541-14001-6K1402-B04-6, \#12541-14001-6K1402-B04-7, \#12541-14001-6K1402-B04-12, \#12541-14001-6K1402-B05, and \#12541-15001-6K1433-B01-2 to B01-32. This work was supported by a JSPS KAKENHI Grant-in-Aid for Scientific Research (C), grant code JP18K06401.

\section{References}

Borda E, Kudenov JD, Chevaldonné P, Blake JA, Desbruyeres D, Fabri MC, Hourdez S, Pleijel F, Shank TM, Wilson NG, Schulze A, Rouse GW (2013) Cryptic species of Archinome (Annelida: Amphinomida) from vents and seeps. Proc Roy Soc B: Biol Sci, 280(1770): 20131876. http://dx.doi.org/10.1098/rspb.2013.1876.

Chen C, Watanabe HK, Ohara Y (2018) A very deep Provanna (Gastropoda: Abyssochrysoidea) discovered from the Shinkai Seep Field, Southern Mariana Forearc. J Mar Biol Assoc UK, 98(3): 439-447.

Chen C, Watanabe HK, Sasaki T (2019) Four new deep-sea provannid snails (Gastropoda: Abyssochrysoidea) discovered from hydrocarbon seep and hydrothermal vents in Japan. Roy Soc Open Sci, 6(7): 190393. http://dx.doi.org/10.1098/rsos.190393. 
Fabri MC, Bargain A, Briand P, Gebruk A, Fouquet Y, Morineaux M, Desbruyeres D (2011) The hydrothermal vent community of a new deep-sea field, Ashadze-1, $1258^{\prime} \mathrm{N}$ on the Mid-Atlantic Ridge. J Mar Biol Assoc UK, 91(1): 1-13.

Firstova A, Stepanova T, Cherkashov G, Goncharov A, Babaeva S (2016) Composition and formation of gabbro-peridotite hosted seafloor massive sulfide deposits from the Ashadze-1 hydrothermal field, MidAtlantic Ridge. Minerals, 6(1): 19. https://doi.org/10.3390/min6010019.

Fouquet Y, Cherkashov G, Charlou JL, Ondréas H, Birot D, Cannat M, Bortnikov N, Silantyev S, Sudarikov S, Cambon-Bonavita MA, Desbruyères D, Fabri MC, Querellou J, Hourdez S, Gebruk A, Sokolova T, Hoisé E, Mercier E, Kohn C, Donval JP, Etoubleau J, Normand A, Stephan M, Briand P, Crozon J, Fernagu P, Buffier E (2008) Serpentine cruise - ultramafic hosted hydrothermal deposits on the Mid-Atlantic Ridge: First submersible studies on Ashadze 1 and 2, Logatchev 2 and Krasnov vent fields. InterRidge News, 17: 16-21.

Kojima S, Ohta S (1997) Calyptogena okutanii n. sp., a sibling species of Calyptogena soyoae Okutani, 1957 (Bivalvia: Vesicomyidae). Venus, 56(3): 189-195.

Kumar S, Stecher G, Tamura K (2016) MEGA7: Molecular Evolutionary Genetics Analysis version 7.0 for bigger datasets. Mol Biol Evol, 33: 1870-1874.

Morineaux M, Nishi E, Ormos A, Mouchel O (2010) A new species of Phyllochaetopterus (Annelida: Chaetopteridae) from deep-sea hydrothermal Ashadze-1 vent field, Mid-Atlantic Ridge: taxonomical description and partial COI DNA sequence. Cah Biol Mar, 51(3): 239-248.

Nishi E, Rouse GW (2014) First whale fall chaetopterid; a gigantic new species of Phyllochaetopterus (Chaetopteridae: Annelida) from the deep sea off California. Proc Biol Soc Wash, 126(4): 287-298.

Ohara Y, Reagan MK, Fujikura K, Watanabe H, Michibayashi K, Ishii T, Pujana I, Martinez F, Girard G, Ribeiro J, Brounce M, Komori N, Kino M (2012). A serpentinite-hosted ecosystem in the Southern Mariana Forearc. Proc Nat Acad Sci, 109(8): 2831-2835.
Okumura T, Ohara Y, Stern RJ, Yamanaka T, Onishi Y, Watanabe H, Chen C, Bloomer SH, Pujana I, Sakai S, Ishii T, Takai K (2016) Brucite chimney formation and carbonate alteration at the Shinkai Seep Field, a serpentinite-hosted vent system in the southern Mariana forearc. Geochem, Geophys, Geosys, 17(9): 3775-3796.

Okutani T, Fujikura K, Watanabe H, Ohara Y (2013) Calyptogena (Abyssogena) mariana: Discovery of a new vesicomyid clam from the Mariana Trench. Venus, 71: 39-47.

Onishi Y, Yamanaka T, Okumura T, Kawagucci S, Watanabe HK, Ohara Y (2018) Evaluation of nutrient and energy sources of the deepest known serpentinite-hosted ecosystem using stable carbon, nitrogen, and sulfur isotopes. PLoS One, 13(6): e0199000. https://doi. org/10.1371/journal.pone.0199000.

Puillandre N, Lambert A, Brouillet S, Achas G (2012) ABGD, Automatic Barcode Gap Discovery for primary species delimitation. Mol Ecol, 21(8): 1864-1877. https://doi.org/10.1111/j.1365-294X.2011.05239.x Available at: https://bioinfo.mnhn.fr/abi/public/abgd/abgdweb.html

Sigwart JD, Chen C (2018) Life history, patchy distribution, and patchy taxonomy in a shallow-water invertebrate (Mollusca: Polyplacophora: Lepidopleurida). Mar Biodiv, 48(4): 1867-1877.

Watanabe H, Seo E, Takahashi Y, Yoshida T, Kojima S, Fujikura K, Miyake H (2013) Spatial distribution of sister species of vesicomyid bivalves Calyptogena okutanii and Calyptogena soyoae along an environmental gradient in chemosynthetic biological communities in Japan. J Oceanogr, 69(1): 129-134.

Zhang J, Kapli P, Pavlidis P, Stamatakis A (2013) A general species delimitation method with applications to phylogenetic placements. Bioinformatics, 29(22): 2869-2876. doi.org/10.1093/bioinformatics/btt499 Available at: https://species.h-its.org/ptp/

Zhou Y, Chen C, Sun Y, Watanabe HK, Zhang R, Wang C (2019) Amphisamytha (Annelida: Ampharetidae) from Indian Ocean hydrothermal vents: Biogeographic implications. Deep-Sea Res Part I: Oceanogr Res Papers, 154: 103148. https://doi.org/10.1016/j.dsr.2019. 103148 . 